\title{
ДОРОГИЕ ДЕТИ, БЕДНЫЕ МАТЕРИ
}

\section{Рецензия на книгу Анны Шадриной «Дорогие дети. Сокращение рождаемости и рост «цены» материнства в XXI веке»}

\section{ЛюБовь БорусяК}

\begin{abstract}
Новая книга Аннь Шадриной «Дорогие дети. Сокращение рождаемости и рост «цены» материнства в XXI веке», опубликованная издательством «Новое литературное обозрение» в мае 2018 г. была награждена премией «ЛибМиссия» в номинации «Аналитика». Эта книга не является строго научной, академической, хотя базируется на большом теоретическом материале, автор хорошо знакома с научной литературой. Она не является и публицистической, хотя может быть интересна широкому кругу читателей. Как и в своей предыдущей книге, Анна Шадрина пытается осмыслить свой личный опыт: на этот раз сложных отношений с матерью и рефлексию по поводу того, хочет ли она сама стать матерью. В рецензии анализируются основные идеи автора книги по поводу того, насколько в современном мире высоки требования кматерям, как они переживают это давление, как понимается сегодня понятие «ответственного материнства». При этом большое внимание уделяется описанию соотношения биологического и сочиального в материнстве. Кроме научной литературы автор книги использует метод самонаблюдения, она подробно иллюстрирует свои соображения, базируясь на художественных фильмах, сериалах, художественной литературе. Не все главы книги представляются одинаково убедительными, тем не менее, «Дорогие дети» представляют сущчественный интерес для соииологов, психологов, демографов, специиалистов 8 области гендерных исследований.
\end{abstract}

Ключевые слова: материнство, дети, гендер, женская занятость, ответственное материнство, семейные роли, социальные институтьл.

В издательстве «Новое литературное обозрение» вышла вторая книга социолога и журналистки Анны Шадриной: «Дорогие дети. Сокращение рождаемости и рост «цены» материнства в XXI веке» [Шадрина 2017] ${ }^{1}$. Как и ее предыдущая книга «Не замужем. Секс, любовь и семья за пределами брака» [Шадрина 2014], новая книга не является академическим трудом, но и не относится к публицистическому жанру. Пожалуй, для определения жанровой принадлежности ее работ больше всего подходит название рубрики, под которой много лет публикует свои статьи в журнале «Неприкосновенный запас» Алексей Левинсон: «Лирическая социология». С одной стороны, сама Шадрина так объясняет появление своей новой книги: «Эта книга - личный проект. Как большинство моих текстов, она выросла из боли» [7], так же она могла определить и стимул для написания своей первой книги. Тогда она пыталась переосмыслить свой личный опыт драматических отношений с любимым мужчиной, на этот раз книгу предваряет посвящение «Моей маме», она «горела желанием разгадать загадку, которая в тот момент волновала меня больше других: почему мои отношения с мамой - самым близким и дорогим человеком - такие сложные и порой болезненные».

ЛюБОВь ФРИДРИХОВНА БОРУСЯк (lborusyak@hse.ru), НАЦИОНАЛЬНЫЙ ИССЛЕДОВАТЕЛЬСКИЙ УНИВЕРСИТЕТ «ВЫСШАЯ ШКОЛА ЭКОНОМИКИ», РОССИЯ.

СТАТЬЯ ПОСТУПИЛА В РЕДАКЦИЮ В МАЕ 2018 Г.

\footnotetext{
${ }^{1}$ Далее при цитировании или отсылке к книге указывается только номер страницы.
} 
Но была и еще одна причина: «Помимо желания выяснить, как устроены наши семейные роли, у меня была еще одна важная причина для изучения социального института материнства - я надеялась разобраться с собственными репродуктивными намерениями» [7]. На пороге 40-летия автор книги пыталась с ее помощью переосмыслить свои детские обиды и понять, хочет ли она стать матерью, как в прошлый раз ей важно было понять, как живут и что чувствуют женщины, выбравшие жизнь «соло». При этом книги Шадриной вполне фундированные, при их написании она опирается на большое количество литературы, сама проводит исследования - интервью и фокус-группы. Замысел своей книги она формулирует следующим образом: «Обобщая, можно сказать, что центральным фокусом данной работы являются превращения образа матери в культуре на фоне драматических социальных перемен» [32].

В центре ее интересов современные российские и белорусские женщины преимущественно образованные представительницы той группы населения, которую у нас с некоторой условностью принято называть средним классом. Она сама относится к этой группе, следовательно, сталкивается с теми же проблемами, что и они, поэтому один из ее исследовательских методов - самонаблюдение. В начале новой книги она специально обращает внимание на то, что она дочь, у которой сложно складывались отношения с матерью, но сама она (пока) не мать, а потому не может опираться на собственный материнский опыт. Впрочем, в пятой главе в параграфе «Как я была няней» она описывает свой опыт ухода за маленьким мальчиком, который помог ей отчасти почувствовать те проблемы, с которыми сталкиваются современные мамы. Вопрос о том, нужно ли социологу прожить и прочувствовать то, о чем он(а) пишет, остается открытым.

Анна Шадрина честно и открыто заявляет в своих книгах, что они и о ней, о проблемах, которые ее волнуют не только как исследователя, но и как человека, женщину. О такой побудительной причине редко говорят и пишут социологи, но на самом деле такой побудительный мотив совсем не редок: какая-то социальная проблема затрагивает его сначала как человека, личность, гражданина, а потом исследователь начинает свою профессиональную работу. Единственная проблема при этом - необходимость по возможности быть максимально нейтральным, чтобы собственные эмоции и представления не делали исследование смещенным. Всегда ли это удается Шадриной? На мой взгляд, не всегда, хотя она и старается этого добиться, опираясь на знание литературы, разных мнений по той или иной теме.

Название книги «Дорогие дети» сразу вызывает ряд ассоциаций, и тут виден журналистский опыт автора. Эти дети дорогие, потому что любимые. Они дорогие, потому что дорого (тяжело) достаются матерям, они дорогие и потому, что сегодня их воспитание, образование, развитие, обеспечение всем необходимым требует немало денежных средств, это «недешевое удовольствие». В книге с той или иной степенью успешности сделана попытка разобраться со всеми этими компонентами материнско-детских отношений. А вот часть подзаголовка («Сокращение рождаемости») не должна вводить читателей в заблуждение. Собственно о снижении рождаемости в книге говорится довольно мало. Низкая рождаемость - это в большей степени тот фон, на котором разворачивается исследование сложностей современного материнства. 
«Дорогие дети» состоят из подробного пролога, где автор рассказывает свою личную историю, шести глав и эпилога. Сразу отмечу, что одна из глав не очень логически связана с основным посылом книги, больше напоминает вставную новеллу, возможно, это подход к следующей книге. Я имею в виду главу четвертую «Семейные ценности» против семьи, или Кто расшатывает брачную лодку?»

\section{БЫТЬ, КАЗАТЬСЯ И ЧУВСТВОВАТЬ СЕБЯ ХОРОШЕЙ МАТЕРЬЮ: ЧТО ИЗ ЭТОГО возМОЖНо?}

Первая глава книги называется «Материнская теория: можно ли быть «хорошей матерью»?» Это главный для всей книги вопрос, на него сразу дается отрицательный ответ, который потом будет с разных сторон рассматриваться на протяжении всего повествования. Правда, в самом названии заключается некоторое лукавство: речь идет не о том, что такое быmь хорошей матерью, это тема не для социолога, а о том, может ли современная женщина, осуществляющая «ответственное материнствование», как это часто обозначается в книге, чувствовать себя хорошей матерью, какие коннотации включает сегодня это понятие и чего ждет общество от «хорошей матери». По мнению автора, современная мать остро чувствует свою ответственность перед ребенком, референтной группой, обществом за выполнение своих материнских функций и всегда испытывает чувство вины, потому что эти требования завышены до уровня невыполнимости. Да еще при этом она должна испытывать счастье от своего материнства, потому что быть матерью, с точки зрения общества, это именно безоблачное счастье. Она не имеет права уставать, раздражаться, сердиться на ребенка, потому что это противоречит суровым социальным ожиданиям. Вот наиболее характерные цитаты по этому поводу: «Публичные атаки на матерей в медиа отражают общественную ситуацию, которую многие женщины, согласившиеся дать интервью для моей книги, описывают так: «Современная мать должна всем, но странным образом, ей никто ничего не должен» [18], «У современной матери нет права быть такой, какая она есть, - она обязывается соответствовать размытому и неуловимому идеалу «хорошей матери» [19]. А поскольку этот образ неуловим, то он недостижим по определению.

Автор пишет о принудительности мнения, что женщине сама природа предписывает заботиться, не получая ответной заботы, дети - это только ее зона ответственности, и как бы ни высока была эта ответственность, она должна (общество ее обязывает) заниматься всем этим не только с готовностью, но и с любовью и удовольствием. Она не имеет права открыть свои переживания, свою неудовлетворенность жизнью (вплоть до рефлексии, а нужно ли ей было заводить детей). Шадрина, и это видно из всего текста, категорически не приемлет такую ситуацию, она кажется ей несправедливой, невротизирующей миллионы женщин, а потому «Я предпринимаю попытку демистифицировать идею «естественного материнского блаженства», натурализирующую труд матери как «биологическую потребность заботиться о других» [35].

Демистифицируя потребность в материнской заботе как естественное предназначение женщины, автор книги обращается к истории, показывая на примерах из научной литературы, что полная ответственность за ребенка присуща далеко не всем 
историческим периодам и не всем культурам. Столь высокой, как сейчас, она, по-видимому, не было никогда. Не очень удачным мне кажется пример Анны Карениной, которую никто не обвинял в том, что она плохая мать, в качестве подтверждения тезиса, что такие обвинения не предъявлялись в XIX веке. Во-первых, Толстой постоянно делает акцент на ее глубокой любви к сыну Сереже. Он как бы заранее снимает возможные обвинения в слабом материнском чувстве. В этом, кстати, отличие от ее отношения к дочери Ане: здесь слабую материнскую привязанность Толстой подчеркивает, например, сообщая, что Аннамать не знает, сколько у маленькой дочки зубов, т.е. передоверив малышку няне, она устранилась от ее воспитания. А во-вторых, все-таки главной темой этой линии романа Льва Толстого является борьба между страстью и супружеским долгом, а не между страстью и долгом материнским.

Анна Шадрина очень много пишет о том, что страдающие от усталости, перегруженности заботами по уходу за домом и ребенком женщины боятся открыться перед другими как в личном общении, так и в социальных сетях. Они вынуждены скрывать свои чувства, опасаясь осуждения, а потому выкладывают в Интернет красивые фотографии с прелестными нарядными детьми и подписями, где сообщает о своем безмятежном материнском счастье. В результате идет цепная реакция: все презентуют «материнское блаженство» и, хотя сами не вполне искренни, верят, что у других все обстоит именно так. А потому они плохие матери, другие ведь вполне счастливы и гораздо лучше выполняют свои семейные и материнские обязанности.

Сделаю небольшую ремарку. Несколько лет назад действительно преобладала именно такая риторика, но в последние два-три года произошли существенные изменения. Я много лет занимаюсь мониторингом обсуждений на родительских форумах и в сообществах в социальных сетях, и эти изменения там видны очень четко, причем происходят с большим ускорением. С одной стороны, популярными остаются прежние форматы материнской самопрезентации: посты о своей безграничной любви к ребенку (детям), фотографии улыбающихся ухоженных мам с детьми. С другой - несколько лет назад появились как своего рода «материнское диссидентство», постепенно переходящие в мейнстрим посты, где женщины пишут о своей невыносимой усталости, послеродовой депрессии, отсутствии времени «для себя» (очень часто это подтверждается такого рода примерами: «Я уже три года в туалет одна пойти не могу», «В душе бываю раз в неделю и то пять минут», т.е. не могут удовлетворить самые элементарные базовые потребности). Очень часто пишут о своей замкнутости только на ребенке, отсутствии общения: «Я обожаю своих детей, но живу, как в тюрьме, запертая ото всего мира» и др. Становится модным показать полную невыносимость для молодых матерей такой ситуации и ее безысходность, отсутствие приемлемого выхода. Во многих дискуссиях в Интернете идет соревнование между мамами, кому живется тяжелее. Каждая находит аргументы, почему именно она страдает больше. С одной стороны, такое самоотречение должно подчеркнуть героизм материнства, пусть признанный только такими же товарищами по (не)счастью. Как правило, такие посты заканчиваются словами о том, что самопожертвование не напрасно, женщина идет на него ради самого ценного - ребенка. Но это является прямым подтверждением тезиса Анны Шадриной о том, что «материнское блаженство» не имеет биологического основания. С другой стороны, это такая пассивная форма борьбы со 
стереотипными представлениями о том, что материнство достается без больших усилий. И здесь они адресуются уже не к референтной группе матерей, а ко всему обществу.

Важно, что представления о норме не статичны, они меняются. Ведь повествуя о своих тяготах, женщины ожидают сочувствия и уважения со стороны общества за свой невидимый и неоплачиваемый труд, а это уже не чувство вины за плохое выполнение материнских обязанностей. Ведь если материнство - это героизм, то общество должно поощрять героев на символическом уровне. Но пока в основном сохраняется представление о том, что все эти тяготы с женщиной не должны делить другие члены семьи, в том числе мужья. Некоторые женщины с гордостью сообщают, что мужья им помогают в уходе за ребенком, но это не стало нормой, это, скорее, особая ситуация. В представлении матерей, в том числе образованных представительниц среднего класса, дом и дети - это по-прежнему в основном зона женской ответственности. Очень редко проблематизируется норма, которая подробно анализируется в книге, что хорошая мать должна быть самоотверженной, что интересы ребенка преобладают над интересами матери. Как бы ни уставала женщина, как бы тяжело ей не давалось материнство, она обязана дать ребенку все, в чем он имеет потребность, а свои потребности ребенок знает. Правда, все чаще появляются посты в социальных сетях и на материнских форумах, где женщины сообщают, что не считают нужным заниматься с детьми ранним развитием, гулять два раза в день и др., но такие матери заранее, защищаясь, называют себя «ехиднами», а реакция на их высказывания бывает достаточно бурной и противоречивой. При этом такие недавно возникшие, но жесткие нормы, как необходимость длительного грудного вскармливания (ребенок должен «висеть на груди», чтобы получить еду в любое время, когда она потребуется), совместного с ребенком сна и другие, не подвергаются сомнению. За исключением слишком радикальных высказываний: если женщина сообщает, что кормит ребенка грудью больше трех лет, это тоже вызывает у многих негодование.

\section{ХОРОШАЯ МАТЬ И ЕЕ РАБОТА}

Анна Шадрина пишет: «От современной матери ожидается нацеленность на профессиональное и непрерывное выполнение постоянно расширяющегося списка навыков: медицинских, педагогических, психологических, менеджерских. Предполагается, что интенсивный уход - наилучшая из известных концепций, соответствующая потребностям женщин и детей» [110]. Хотя некоторые экспектации из этого набора сейчас начали подвергаться сомнению, но в целом они сохраняются. Не вызывает сомнений и представление о том, что никто не может обеспечить ребенку уход такого качества, как мать. Все замещающие мать лица воспринимаются как допустимые, но уступающие матери в этой роли. Характерно, что сохраняется традиционалистское представление о том, что уход за ребенком - это женское дело, недоступное мужчинам, поэтому замещающим лицом могут быть няни и бабушки, но не отцы детей. Их дело (и здесь Россия пока весьма патриархальна) обеспечивать семью деньгами, «приносить мамонта», как это принято формулировать на материнских форумах.

Тема работающих матерей, их проблем и отношения к ним общества, одна из важных в книге «Дорогие дети»: «Если целью советской семейной политики виделось 
содействие женщинам в совмещении семейных функций и работы вне дома, то нынешний внутриполитический курс провозглашает одомашнивание женщин наилучшим решением проблемы. Очевидно, что такой план реализуем только в контексте гетеросексуального брачного союза» [174]. То, что консервативный политический курс ориентирует женщин на максимально «полноценное» выполнение своих «данных природой» функций, несомненно. Сами женщины эту государственную риторику хорошо знают, а потому часто в ходе интернет-обсуждений обиженно пишут, что государство призывает их рожать, но помощи почти не оказывает. Шадрина часто сравнивает ситуацию при социализме, когда государство помогало женщинам-матерям, с современной капиталистической ситуацией, когда оно стремится устраниться от своих социальных обязанностей. Я не уверена, что для описания ситуации релевантна марксистская теория, хотя бы потому, что современная ситуация не укладывается в рамки этой теории. Есть страны, прежде всего Скандинавские, где помощь государства семьям с детьми огромна, значительно больше, чем была во времена СССР. Есть страны, где государство гораздо меньше помогает семьям (например, США). Поскольку в задачи автора не входил анализ социально-политической системы разных стран, то мне кажется, что анализ, основанный на противопоставлении «при капитализме так, а при социализме иначе», не очень удачен, плохо объясняет происходящие перемены.

Автор книги справедливо пишет, что очень жестко нормативными в современной России стали представления, что до 3 лет ребенок должен быть с матерью, что он объективно, биологически в этом нуждается и без этого страдает. Это означает, что без крайней необходимости женщине не следует выходить на работу до достижения ребенком этого возраста. Но довольно слабо прописано, как сформировалась эта норма. Справедливо указано, что и в послесоветское время отдавать детей в ясли, особенно на пятидневку, считалось нежелательным. Предпочтительным было доверить ребенка замечающему мать лицу, в основном бабушке. После того, как в соответствии с п.2 Постановления Совета Министров СССР и ВЦСПС от 22 августа 1989 г. №677 "Об увеличении продолжительности отпусков женщинам, имеющим малолетних детей", отпуск по уходу (с сохранением стажа) был продлен до трех лет, начала формироваться эта норма. Тем более, что это происходило на фоне мощной государственной пропаганды важности длительной «полноценной» материнской заботы для детей. Данный период характеризуется выраженной пронаталистской государственной демографической политикой, о чем упоминается в книге.

В ситуации детоцентризма, когда потребности детей ставятся выше потребностей остальных членов семьи, а также консервативной государственной риторики о женском предназначении выбор, сколько времени находиться с ребенком до выхода на работу и выходить ли вообще, часто приобретает драматический характер, но все-таки далеко не всегда. Как в советское, так и в постсоветское время, один кормилец в абсолютном числе семей не мог и не может обеспечить семье приемлемый уровень жизни, особенно сегодня, когда стандарты существенно выросли. Не говоря о том, что женщины понимают, как хрупок сегодня брак, а оставшись без мужа и без работы, но с детьми, они неизбежно окажутся в сложнейшей ситуации. Не случайно сегодня стандартным стало: «Кроме нас (матерей - ЛБ) наш ребенок никому не нужен». «Мы», т.е. матери, противопоставляются 
«им», т.е. государственным институтам, а зачастую и мужу, отцу ребенка. Единственные, от кого зависит жизнь и будущее ребенка, - это только матери. Поэтому на уровне риторики женщины могут поддерживать традиционные ценности (как они их понимают), но на уровне практик возвращаться к чисто домашней жизни хотят или решаются очень немногие. Вопрос только в том, сколько нужно неотрывно заниматься ребенком.

И вот тут норма «с ребенком надо быть до трех лет» действует достаточно жестко. Недавно мне пришлось читать очень активную дискуссию на материнском форуме, инициированную женщиной, имеющую двух достаточно взрослых сыновей, родившей дочь и практически сразу вернувшейся на работу. У нее свой бизнес, который требует постоянного контроля. В качестве оправдания, что она доверила дочь няне, она сообщила, что продолжает грудное вскармливание: замораживает грудное молоко. Поскольку речь не шла о выживании матери и ребенка (семья хорошо обеспеченная), то такое поведение женщины ожидаемо вызвало большое возмущение: «Если ребенок тебе не нужен, зачем его рожала?», словно она полностью отказалась от материнской функции. Это вполне согласуется со следующим утверждением автора книги: «Работающие матери, взращивающие новые поколения на пересечении парадигм детоцентризма и глобального капитализма, часто сталкиваются с дискриминирующим суждением: «Для чего нужны дети, если за ними присматривают няни или другие люди?» В ситуации, когда, с одной стороны, культура не изобилует позитивными женскими образами, не связанными с материнством, а с другой стороны, необходимость зарабатывать является безоговорочным условием жизни, эта риторика, не предлагая решения проблемы, лишь внушает современницам чувство вины за несоответствие воображаемому стандарту «хорошей матери» [253].

Маленький ребенок должен быть с матерью - это очень жесткая российская норма. В противном случае он испытает депривацию, будет травмирован, возможно, на всю жизнь. Многие помнят наружную рекламу, которая некоторое время назад была представлена на улицах городов. На постере был изображен мальчик в очках, который что-то вяжет, закусив губу. Слоган: «Весь в няню!» ${ }^{2}$ На сайте социальной рекламы под этом рекламным образцом написано: «Для детей дорога каждая минута, проведенная с мамой и папой. Это единственное, что способно их сделать по-настоящему счастливыми. Сумасшедший ритм жизни с его встречами, дедлайнами, авралами подчас не оставляет современным родителям время на своих детей. Понять взрослых можно - они делают все возможное, чтобы их ребенок ни в чем не нуждался, и они могли бы исполнять все его желания. Но при этом они совершенно забывают, что для малыша проведенное вместе время намного важнее, чем содержимое кошелька». Иными словами, бедность не является причиной выходить на работу, поскольку это идет в ущерб развитию ребенка. И это при том, что ребенок на рекламном баннере не младенец, а старший дошкольник.

Тем не менее, если полная занятость матери маленьких детей вызывает негативное отношение общества, то ее работа из дома или частичная занятость, если мать основную часть времени проводит дома, вполне поддерживается. Хотя очевидно, что при этом

\footnotetext{
${ }^{2}$ URL: http://vse-ravno.net/campaigns/people/vremya-s-detmi (дата обращения: 05.05.2018). 
женщины испытывают очень большие нагрузки: ребенок, работа, домашние обязанности. И если неработающие матери уже начали испытывать сочувствие за свое самопожертвование, то частично работающие или работающие из дома - в значительно меньшей степени. Предполагается, что это их собственный выбор. Между тем во многих странах считается нормой в двух-трехмесячном возрасте выходить на работу и отдавать ребенка в детский сад или нанимать няню. При этом женщины не испытывают выраженного чувства вины и не считают, что наносят ребенку травму. Но это происходит в тех странах, где женщины не имеют права на длительный отпуск по уходу за ребенком.

Понятно, что возвращение женщины к трудовой деятельности у нас является нормой уже много десятилетий, и теперь это остается нормой, особенно если речь идет не о младенцах, а о детях постарше. Шадрина пишет: «В наши дни большинство женщин совмещают материнство и профессиональную занятость. Но текущая концепция материнствования, подразумевающая интенсивное погружение в заботу о детях, плохо согласуется с нарастающей соревновательностью на рынке труда. В условиях неолиберального поворота ответственность за детскую дошкольную социализацию постепенно передается семьям: время «декретных» отпусков увеличивается, в то время как количество детских садов и яслей сокращается» [218]. Отсюда необходимость в использовании замещающих лиц для ухода за ребенком. Отметим, что все-таки большинство детей старше 3 лет по-прежнему посещает детские сады, сокращение мест в детских дошкольных учреждениях коснулось, прежде всего, яслей. Поэтому не вполне справедливым кажется утверждение, что происходит переход к домашнему дошкольному воспитанию детей. Но кто становится замещающим мать лицом?

В книге написано: «Увеличивается количество работающих пенсионеров, в связи с чем сокращается помощь «института бабушек». В такой ситуации все большее количество семей вынуждено переадресовывать часть домашнего труда наемным специалисткам» [219]. И вот с тезисом о том, что матери именно вынуждены передавать часть домашнего труда наемным специалистам, хочется поспорить. В некоторых случаях это именно так, особенно если семья испытывает значительные финансовые трудности, но во многих дело обстоит иначе. Знаменитый советский «институт бабушек» переживает кризис не только из-за того, что они сами работают, а потому не могут и не хотят «сидеть» с внуками. Если есть финансовая возможность, многие мамы предпочитают нанять няню, а не использовать помощь своей матери (свекровям детей доверяют вообще значительно реже). Почему? Отчасти ответ есть в шестой главе книги «Жизнь без боли»: детская психологическая травма как продукт», значительная часть которой посвящена сложным отношениям взрослых женщин с мамами. В том числе Шадрина пишет и о своих сложных отношениях с матерью. Правда, она не переносит эту проблему на выбор няни как предпочтительной альтернативы бабушке. Один из параграфов главы называется «Почему мама «вмешивается»?» Речь идет о том, что мамы вполне взрослых женщин «вмешиваются» в их жизнь, пытаются сохранять свою власть, какой она была, когда дочка была ребенком. Но молодые женщины не хотят, чтобы бабушки «вмешивались» в воспитание их детей, они это воспринимают как вторжение в свою и только свою зону ответственности. Они могут требовать от няни выполнять свои требования, от своей мамы они и хотели бы требовать того же, но не получается. Я множество раз читала возмущенные высказывания молодых 
мам, что бабушки их не слушают, делают все по-своему, а их опыт устарел, они портят внуков. Идеальная бабушка в этом смысле это та, которая понимает, что дочь оказывает ей большую честь, разрешая оставаться с внуками, а потому выполняет все ее требования. При этом безвозмездно в большинстве случаев. Бабушки же расценивают свой уход за внуками как помощь дочери, за которую та должна быть благодарна, а потому считают себя вправе самой решать, как воспитывать детей. Фактически здесь речь идет о власти и статусе. В советское время, когда бабушкам не было замены, эта власть была на их стороне. Сейчас, если дочь способна нанять няню, даже если это для ее семьи тяжело финансово, она считает, что ее материнский статус выше, а потому ее мать должна начать подчиняться требованиям.

В целом в книге очень подробно и интересно анализируются отношения двух взрослых женщин, а затем Шадрина переходит к анализу чрезвычайно актуальной для сегодняшнего социума детской травмы. Сама автор пишет, что, много общаясь с матерью, работая над книгой, смогла пережить свои детские травмы, взглянула на них новыми, «взрослыми» глазами, встала на позицию своей матери и отпустила детские обиды.

Что касается современных материнско-детских отношений, то причины такого мощного давления на матерей, любой неверный шаг которых в воспитании приводит к детским травмам, она объясняет так: «Практика призывания к жизни подвергнутых цензуре переживаний, критическое осмысление категории «счастья», интернализация понятия «психологическая травма» являются результатом перехода от культурной логики, действующей при социализме, к новой, капиталистической идеологии. С отменой «железного занавеса» и приходом популярной психологии в «нашу часть света» к функции контроля над эмоциями присоединяется рынок и тот новый экспертный институт, который он предлагает» [290]. Я не уверена, что муссирование, в том числе коммерческое, детских травм это результат перехода России от социализма к капитализму, что здесь правомерна такая теоретическая рамка. Мне она кажется слабо объяснительный. Тем не менее сам разговор о детских травмах как важном конструкте материнско-детских отношений кажется очень важным и своевременным. В частности, это относится к дисциплинирующей матерей концепции воспитания, основанной на обязательном счастье детей: «Несмотря на всю эфемерность, знак счастья является реально действующей дисциплинирующей категорией. В культуре «принудительного счастья» любые жизненные сложности, препятствия на пути к удовлетворению желаний и неудачи описываются не как условия для развития личности, но как провал взрослых, прежде всего, матерей, не сумевших обеспечить эмоциональную безопасность для своих детей» [290].

\section{ЗАКЛЮЧЕНИЕ}

Конечно, в этой книге есть немало мелких ошибок. Например, медикализация беременности и родов началась в 1920-е, а не в 1930-е годы [119]. Или на странице 133 сказано, что к 1970 г. 51\% женщин работали вне дома, а это доля женщин среди занятых внедомашним трудом, а не среди всех женщин. Проблема проживания детей не с родителями, а с другими родственниками начала обсуждаться не в начале XXI века [159], а значительно раньше. Об этом, например, песня группы «Верасы» «Я у бабушки живу, я у дедушки живу», очень популярная еще в 1970-е годы. Не очень удачными являются многие 
примеры фильмов, приведенные в третьей главе «Родина-мать, мать и мачеха: превращения (пост)советского материнства». На примере фильмов, снятых в разные десятилетия, автор пыталась показать «как меняющиеся представления о роли матери отражаются в культуре» [137]. Сам прием вполне допустим: показывая материнско-детскую риторику разных эпох, можно сделать вполне валидные выводы. Но в данном случае попытка, как мне кажется, удалась далеко не полностью. У автора была концепция, что происходило в тот или иной период времени, под эту концепцию она, хотя и не всегда с точным попаданием, подбирала фильмы. Мне кажется, что более правильным было бы поступать наоборот: анализировать фильмы разных десятилетий и на их основе формировать свою концепцию, но тогда не удалось бы ограничиться четырьмя фильмами за 10-летний период. Очень жаль, что в результате очень важные фильмы, не укладывающиеся в концепцию, в анализ не попали. Например, вызвавший в свое время огромную дискуссию фильм Юлия Райзмана «Странная женщина» с Ириной Купченко в главной роли. В этом фильме женщина уезжает из дома в поисках себя, оставив не только мужа, но и сына, т.е. она поставила самоактуализацию выше своей материнской функции. Насколько я могу судить, это был первый пример такого рода в советском кино. Да и само описание материнства в ту или иную эпоху не всегда релевантно ситуации. В частности, не очень понятна идея 1970-х годов: «В 1970-ые годы начинает ставиться под сомнение идея полностью обобществленного воспитания детей» [141]. К тому времени эта идея давно выглядела анахронизмом.

Кроме того, сама периодизация не всегда позволяла при небольшом числе фильмов (4 на каждое десятилетие) увидеть главные тренды, потому что внутри временного промежутка происходили коренные изменения. Это относится и к 40-м годам и особенно к перестроечному и постсоветскому периоду.

Уже отмечалось, что одна из глав не имеет непосредственного отношения к теме книги. В четвертой главе «Семейные ценности» против семьи, или Кто расшатывает семейную лодку» [166-217] очень мало говорится о материнско-детских отношениях, почти вся глава посвящена отношениям женщин с реальными или потенциальными партнерами, причем эти отношения автор критикует с феминистских позиций как крайне неравноправные, не партнерские. Между тем, анализ почти полностью построен на очень подробном описании телесериала Валерии Гай Германики «Краткий курс счастливой жизни». Далеко не всё из написанного кажется убедительным, но не очень понятно, зачем этот сюжет необходим именно для книги «Дорогие дети».

Тем не менее книга Анны Шадриной «Дорогие дети» мне кажется очень важной. Это весьма серьезная заявка на описание и анализ очень сложной и болезненной социальной проблемы: почему материнство как социальный институт в его современном понимании порождает мощные напряжения у женщин в их материнской роли. В начале книги, как уже цитировалось выше, автор книги писала о том, что ее исследование должно было внести ясность в ее собственные репродуктивные намерения. Этой ясности исследование ей не дало. Возможно потому, что она четко определила проблемы, но не увидела никаких путей для их решения. 


\section{ЛИТЕРАТУРА}

Шадрина А. (2014). Не замужем. Секс, любовь и семья за пределами брака. М.: Новое литературное обозрение. 240 с.

Шадрина А. (2017). Дорогие дети. Сокращение рождаемости и рост «цены» материнства в XXI веке. М.: Новое литературное обозрение. 392 с. 


\section{PRECIOUS CHILDREN, POOR MOTHERS \\ Review of Anna Shadrina's book "Precious children: The fall in fertility and the rise in the price of motherhood in the 21st century"}

\section{LIUBOV BORUSYAK}

The new book by Anna Shadrina, "Precious Children: The fall in fertility and the rise in the price of motherhood in the 21st century," published by the New Literary Observer in May 2018, won the "LibMissiya" Prize for Analytics. While not, strictly speaking, an academic book, it is based on a broad theoretical foundation and the author is well versed in current research. But the book is not journalistic either, although it will be of interest to large audiences. As in her previous book, Anna Shadrina tries here to make sense of her personal experience - in this case, of the complex relationship with her mother and her reflections on whether she wants to become a mother herself. This review analyses the book's main ideas: how great are the demands made on mothers by modern society, how mothers experience this pressure, and how "responsible motherhood" is understood today. Anna Shadrina focuses particularly on the interrelation between the biological and the social aspects of motherhood. In addition to scientific literature, she uses the method of introspection and illustrates her ideas using movies, TV series, and fiction. Not all chapters are equally convincing, yet "Precious Children" is of significant interest for sociologists, psychologists, demographers, and scholars in gender studies.

Key words: motherhood, children, gender, female employment, responsible motherhood, family roles, social institutions.

LiUbov Borusyak (lborusyak@hse.ru), NATIONAL RESEARCH UNIVERSITY HighER SCHOOL OF EcONOMics, RuSSIA.

DATE RECEIVED : MAY 2018.

\section{REFERENCES}

Shadrina A. (2014). Ne zamuzhem. Seks, lyubov' i sem'ya za predelami braka [Not married. Sex, love and family outside marriage]. Moscow: Novoe literaturnoe obozrenie. 240 p.

Shadrina A. (2017). Dorogie deti. Sokrashchenie rozhdaemosti i rost «tseny» materinstva v XXI veke [Precious Children: The fall in fertility and the rise in the price of motherhood in the 21st century]. Moscow: Novoe literaturnoe obozrenie. 392 p. 